
OF THE ILLUSION.

\author{
BY C. W. VALENTINE. \\ Lecturer in Psychology, etc. to the St Andrews Provincial Committee for \\ the Training of Teachers. \\ I. Method of Experiment. \\ II. and III. First and second tests of the effect of astigmatism. \\ IV. The testing of subjects with and without correcting \\ cylindrical glasses. \\ V. Evidence of a physiological factor other than that of \\ astigmatism. \\ VI. The effect of practice on the illusion. \\ VII. Interpretation of the effects of practice. \\ VIII. The nature of the physiological factor involved in the \\ illusion.
}

IX. Summary of results and conclusions.

IN a previous paper ${ }^{1}$ the writer attempted to show that no psychological theory yet put forward can satisfactorily explain the usual overestimation of a vertical line when compared with an adjoining horizontal. The purpose of the present paper is to adduce reasons for accepting a physiological rather than a psychological cause of the illusion, or at least to show that some physiological factor plays an important part in the illusion.

This idea was suggested to me by the fact that in the case of my first subject W. A. in the previous set of experiments, a notable difference was manifest between the number of times the illusion occurred when the right eye only was used and the number when the left eye only was used. The results for the subject E. R. V. (loc. cit., Tables VI, VII, VIII, and IX) showed a greater illusion for the left eye than for the right in

1 This Journal, 1912, v. 8-35. 
three of the four figures $(B, C$, and $D)$, the difference being as much as $1.5 \mathrm{~mm}$. in each case, when the vertical was standard ${ }^{1}$. In table XI (loc. cit.) subject A. D. showed a greater amount of illusion for the left eye, and subject A.S. for the right eye with all three standards $(40 \mathrm{~mm}$., $60 \mathrm{~mm}$., and $100 \mathrm{~mm}$.). I do not wish to put too much reliance upon results gained by the method of mean error, but the agreement of the results of experiments in which three different standards were employed is remarkable.

Thus there was enough evidence to suggest that a physiological factor is at work, and with this suggestion in mind, I have since continued the experiments upon other subjects 2 .

\section{Method of Experiment.}

The experiments were performed in the same way as those described in the former paper, except that the subjects no longer used both eyes together in any of the sittings, the sole purpose now being to discover any differences between the two eyes taken singly.

One important point had to be borne in mind. It was conceivable that astigmatism might affect the amount of the illusion and so be responsible for the difference between the two eyes. Accordingly the following steps were taken.

1. The effects of artificial astigmatism (produced by cylindrical lenses) were tried.

2. I tested the extent of the illusion with each eye in subjects who were quite free from astigmatism. I was only able to obtain two such subjects, L. B. and C. W. V.

3. I tested subjects having a known amount of astigmatism, with and without their compensating glasses,_-subjects C. O. K. and J.S.

4. I tested one subject with a known amount of astigmatism, comparing the difference between the eyes with what it should theoretically be if astigmatism were the cause of the illusion.

It will be convenient to consider first the effect of astigmatism upon the amount of the illusion. It can be shown theoretically that regular

1 The four figures used were as follows: Fig. A L, Fig. B $\lrcorner$, Fig. C ᄀ, Fig. D r. When no other figure is specified the reference is to Fig. $A$.

2 A difference between the results for the right and left eyes respectively can scarcely be due to other than physiological differences. The difference between the contours of the fields of vision of the two eyes, even if sufficient to have any effect, should be a constant difference, i.e. should always make the illusion greater for the same eye. But this is not the case. In some subjects the illusion is greater for the right oye, in others for the left. 
astigmatism (i.e. where the curvature of the cornea requires correction in a vertical direction) tends to blur a horizontal line and slightly lengthen a vertical one'. But if we can show, as I think we can, that the effect of astigmatism cannot account at any rate for all the cases in which the illusion differs for the two eyes we shall have grounds for concluding that some other physiological factor is at work.

\section{First test of the effect of astigmatism.}

As so many people are slightly astigmatic, it was highly important to determine to what extent a slight degree of astigmatism can affect the clearness of the kind of lines used. To ascertain this various tests were adopted. In the first test I used a cross consisting of black lines at right angles on a white card. I looked at this cross through cylindrical lenses of various strengths (such as are used to correct astigmatism), thus creating artificial astigmatism. Here I had the kind assistance of Dr A. Bradburne of Southport, who fitted the various glasses upon me without my knowing. their strength or nature.

The tests were carried out both with the right and left eyes, taken separately and with both eyes together. The axes of the lenses were placed vertically, i.e. the horizontal curvature was the one that was affected. I also wore my usual glasses for correction of myopia. The results were as follows :

Strength of Lens

+1.0 diopter. No discernible difference either for the right or left eye or both together.

+1.5 diopters. The vertical line slightly paler at first, and possibly broader. But this effect soon disappeared, presumably owing to accommodation.

+2.0 diopters. The vertical line distinctly blurred, and horizontal apparently lengthened.

Dr Bradburne repeated the tests upon himself and in every particular confirmed my own observations. The importance of these tests lies in the conclusion that apparently astigmatism of $1 \mathrm{D}$ or less has no effect upon the clearness of such lines, and that any effect due to 1.5 D may be compensated for by accommodation.

1 Cf. H. R. Swanzy, Diseases of the Eye, 1900, 42, 43. 


\section{Second test of the effect of astigmatism.}

Two spectacle frames were fitted, one with a plain lens for the left eye, the other with $a+1.5 \mathrm{D}$ cylindrical lens for the left eye. A series of experiments was then performed similar to those described in my previous paper ${ }^{1}$, with instantaneous exposure of the horizontal-vertical figure. Only the left eye was used. At one sitting the subject was fitted with the plain lens in front of the left eye, the right eye being covered: at the next sitting the cylindrical lens was used, and so on. The plain lens spectacles were simply used as a "blind" so that the subject should not know when artificial astigmatism was being caused.

I myself acted as a subject in this set of experiments, as I had been pronounced entirely free from astigmatism. The results, given in Table I, form a striking confirmation of the preliminary tests. The illusion was practically the same whether the $+1.5 \mathrm{D}$ cylindrical lens was used or not, even the totals of numbers of the various classes of judgments being remarkably alike.

TABLE I. Subject C. W. $V$.

Horizontal Standard, $60 \mathrm{~mm}$.

With Plain Lens.

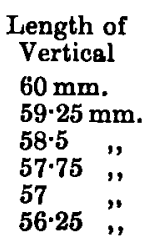

With + 1·5 D Cyl. Lens.

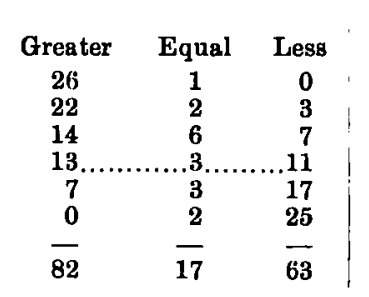

Vertical Standard, $60 \mathrm{~mm}$.

With Plain Lens.

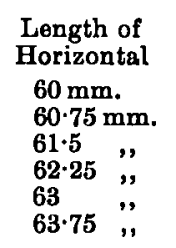

J. of Prych. v
With +1.5 D Cyl. Lens.

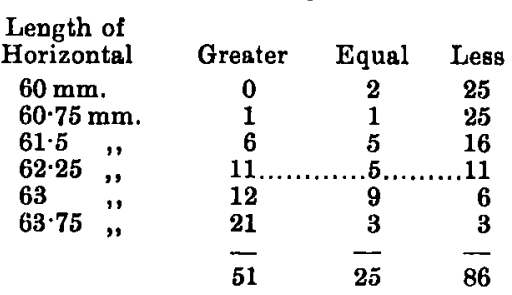

1 Op. cit. 
IV. The testing of subjects with and without correcting cylindrical lenses.

Under this section appear the results of two subjects, J.S. and C. O. K.

The errors of refraction in the case of J.S. are shown by the following prescription recently given him by an emineut oculist.

Right Eye.

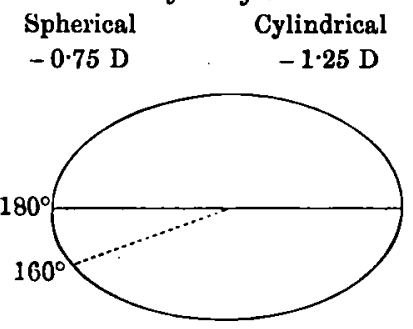

Left Eye.

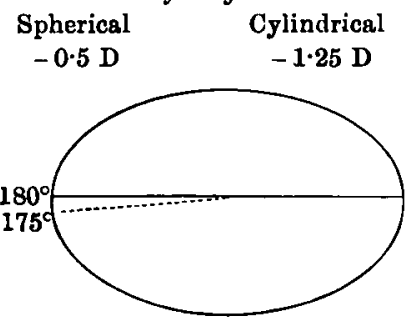

The dotted lines show the position of the axis of the lens: the 'abnormal' meridian of the cornea (i.e. that which needs correction) is at right angles to the dotted line. Table II shows the results of J.S. (i) with glasses according to the above formula, (ii) without glasses.

The glasses were used at alternate sittings. At the first sitting 'with glasses,' the right eye was tested first and then the left eye, and so also for the first sitting ' without glasses.' At the next two sittings the left eye was tested first, and so on, thus equalising any effects of practice or fatigue.

It will be seen that J.S. shows a 'negative' illusion, i.e. he overestimates the horizontal. The difference caused by the removal of the glasses is small, and what difference there is is ambiguous; the removal of the glasses very slightly decreasing the negative illusion for the right eye but increasing it for the left eye. Hence in the subject J. S. we have evidence that astigmatism of $\pm 1.25 \mathrm{D}$ need not affect the illusion.

The results of subject C.O.K. are given in Tables VIII and IX of my previous paper. Her glasses are as follows:

\begin{tabular}{cc|cc}
\multicolumn{2}{c|}{ Right } & Eye. & \multicolumn{2}{c}{ Left } & Eye. \\
Spherical & Cylindrical & Spherical & Cylindrical \\
$-2.25 \mathrm{D}$ & $-1.25 \mathrm{D}$ & $-2.25 \mathrm{D}$ & $-1.25 \mathrm{D}$
\end{tabular}

Now this subject does show a difference in the amount of the illusion according as glasses are used or not. The illusion is nearly

\footnotetext{
1 This Journal, loc. cit. 14, 15.
} 
$2 \mathrm{~mm}$. greater when glasses are not worn. As the axes of the lenses are nearly horizontal ${ }^{\text {, }}$, we should expect that her astigmatism would, if anything, lengthen the vertical, i.e. increase the illusion.

\section{TABLE II. Subject $J$. S.}

Standard Horizontal, $50 \mathrm{~mm}$.

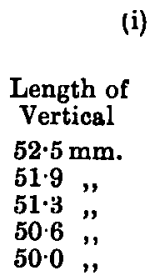

$52.5 \mathrm{~mm}$.

51.9 ,

$51 \cdot 3 "$,

$50 \cdot 6$,"

$50 \cdot 0 "$,

(i) With glasses. Right Eye.

Left Eye.
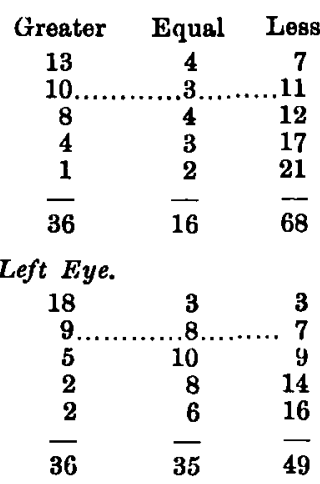

Standard Vertical, $50 \mathrm{~mm}$.

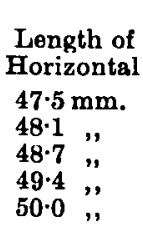

Right Eye.

$\begin{array}{ccc}\text { Greater } & \text { Equal } & \text { Less } \\ 3 & 7 & 14 \\ 8 \ldots \ldots \ldots \ldots .6 & . \ldots \ldots & 9 \\ 12 & 4 & 8 \\ 16 & 4 & 4 \\ 22 & 2 & 0 \\ \frac{61}{61} & -\frac{23}{35} & \overline{35}\end{array}$

Left Eye.

$47 \cdot 5 \mathrm{~mm}$.
$48 \cdot 1=$
$48 \cdot 7 "$,
$49 \cdot 4=$
$50 \cdot 0 "$,
Standard Horizontal, $50 \mathrm{~mm}$.

(ii) Without glasses. Right Eye.

Length of Vertical $52.5 \mathrm{~mm}$. 51.9 , $51 \cdot 3$, 50.6 ,", $50.0 "$

$\begin{array}{ccc}\text { Greater } & \text { Equal } & \text { Juess } \\ 20 & 3 & 4 \\ 12 & \ldots \ldots \ldots \ldots \ldots \ldots \ldots & 7 \\ 8 & 7 & 12 \\ 6 & 8 & 13 \\ 1 & 9 & 17 \\ \frac{1}{47} & \overline{35} & \overline{53}\end{array}$

Left Eye.

$52.5 \mathrm{~mm}$.

51.9 ,"

$51 \cdot 3$,",

$50 \cdot 6 "$

$50 \cdot 0 "$

\begin{tabular}{|c|c|c|}
\hline $17 .$. & .5. & .5 \\
\hline 6 & 8 & 13 \\
\hline 7 & 6 & 14 \\
\hline 4 & 4 & $\begin{array}{l}10 \\
19\end{array}$ \\
\hline & & \\
\hline & 28 & 6 \\
\hline
\end{tabular}

Standard Vertical, $50 \mathrm{~mm}$.

Length of

Right Eye.

\section{Horizontal}

$47.5 \mathrm{~mm}$.

48.1 ,

$48 \cdot 7$,

$49 \cdot 4$,

$50 \cdot 0 "$,

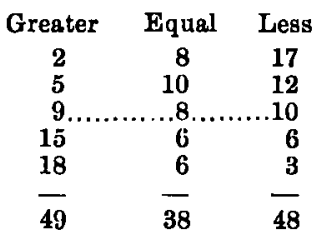

Left Eye.

$47 \cdot 5 \mathrm{~mm}$.
$48 \cdot 1 "$,
$48 \cdot 7 "$,
$49 \cdot 4 "$,
$50 \cdot 0 "$,

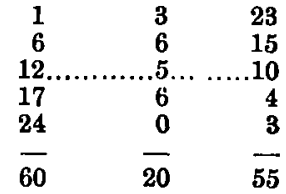

Here then apparently we have an instance in which astigmatism does affect the illusion. Yet the astigmatism is the same in amount as that of subject J.S. and the axes of the lenses are very similar, i.e. not far from the horizontal. What is the cause of the difference in the results given by J.S. and C.O.K. ? One suggestion occurred to me as

1 Ten degrees from the horizontal in the case of each lens. 
the result of an observation when I was a subject for experiments with the cylindrical lenses. I noticed that when using an astigmatic lens, if I did not also wear my usual concave glasses, the horizontal line was distinctly blurred; but this blurring disappeared when I put on my concave glasses. That is, I could correct the artificial astigmatism by accommodation only when my short-sightedness did not also prevent me from getting a clear image of the figure.

It would seem possible then, when the other optical conditions are satisfactory, that the eye can correct slight degrees of astigmatism which otherwise might cause blurriug of one line. Now the one point in which C.O.K. and J.S. differ most markedly is in the degree of their myopia. Whilst C.O.K. has a considerable amount $(-2 \cdot 25 \mathrm{D})$, J.S. has very little $(-0.75 \mathrm{D}$ in the right eye and $-0.5 \mathrm{D}$ in the left). I would suggest then that J.S. was able to correct his astigmatism by accommodation and so get a clear image of the figure, whilst C. O.K. could not fully correct it. This surmise is confirmed by the fact that C. O. K. remarked that the figure appeared blurred to her when she did not use her glasses.

\section{Evidence of a physiological factor other than that of astigmatism.}

As I have already remarked, any difference between the amount of the illusion for the right eye and the amount for the left eye must apparently be referred to physiological causes. Now we have seen that astigmatism of $\pm 1.5 \mathrm{D}$ or less is not likely to affect the amount of the illusion unless it is accompanied by marked defectiveness of vision of another kind. This makes the results of E. R.V. given in the previous paper $^{1}$ of significance. In her case the illusion was greater for the left than for the right eye in three of the four quadrant figures, especially when the vertical was standard, the figure then becoming bigger as a whole. (See especially Table IX $(b)$ where the judgments "vertical greater" are almost exactly twice as numerous for the left eye as for the right. Probably this difference between the two eyes would have been even more marked in this subject if she had been tested by instantaneous instead of by prolonged exposures.) Now this difference cannot, in view of our previous results, be ascribed to astigmatism, as in her case it was very slight, only $+0.5 \mathrm{D}$ for the right eye (axis $45^{\circ}$ from the horizontal) and $+0.75 \mathrm{D}$ for the left eye (axis $15^{\circ}$ from the horizontal). In other

1 This Journal, loc. cit. 19-22. 
respects her eyesight was excellent'. Furthermore, when a cross of two intercepting lines (horizontal and vertical) was looked at by E. R. V. with the left eye, there was scarcely any discernible difference in clearness, the horizontal if anything appeared somewhat clearer, whereas with the right eye both were equally clear.

Important evidence is also afforded by the next two subjects. In the case of C.W.V. there is no astigmatism whatever; yet a marked difference appears between the results for the two eyes, the illusion being twice as great for the right eye as for the left, and three times as great when the vertical is the standard. In the case of subject A. E. T. there is slight astigmatism but it is of such a nature that it should theoretically cause the illusion to be less for the right eye than for the left, whereas it is actually greater for the right eye ${ }^{2}$, and nearly three

TABLE III. Subject A. E. T.

Standard Horizontal, $60 \mathrm{~mm}$.

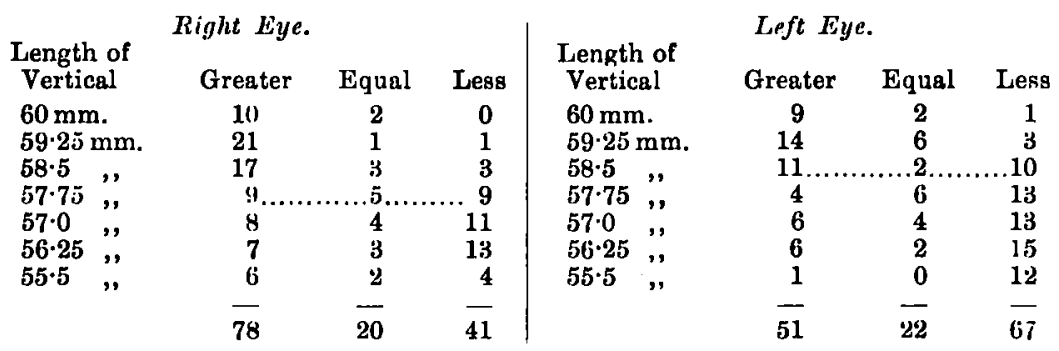

Standard Vertical, $60 \mathrm{~mm}$.

\begin{tabular}{|c|c|c|c|c|c|c|c|}
\hline & ight E'ye & & & & Left $E !$ & & \\
\hline $\begin{array}{l}\text { Length of } \\
\text { Horizontal }\end{array}$ & Greater & Equal & Less & $\begin{array}{l}\text { Length of } \\
\text { Horizontal }\end{array}$ & Greater & Equal & Less \\
\hline $60 \mathrm{~mm}$. & 1 & 2 & 6 & $60 \mathrm{~mm}$. & 0 & 2 & 7 \\
\hline $60.75 \mathrm{~mm}$. & 3 & 3 & 17 & $60.75 \mathrm{~mm}$ & 6. & .3. & $\ldots 14$ \\
\hline $61 \cdot 5 \quad$, & 4 & 2 & 13 & $61.5,$, & 13 & 1 & 9 \\
\hline $62 \cdot 25$, & 5 & 4 & 12 & $62 \cdot 25$, & 14 & 5 & 4 \\
\hline $63 \cdot 0$ & 8 & 4 & 11 & 63.0 & 16 & 1 & 6 \\
\hline 63.75, & 10. & 1. & .12 & 63.75, & 15 & 5 & 3 \\
\hline $64.5 "$ & 13 & 0 & 4 & 64.5, & 15 & 1 & 1 \\
\hline & 44 & 16 & 75 & & $7 y$ & 18 & 44 \\
\hline
\end{tabular}

1 I am indebted to Dr A. McGillivray, Lecturer in Ophthalmology at the University College, Dundee, for his kindness in submitting this subject and also subjects L. B., A. K., J. C. and C. W. V. to a thorough examination for astigmatism and other errors of refraction.

2 This subject's condition was as follows: Right eye, Spherical - 1.0 D, Cylindrical $-0.75 \mathrm{D}$, Axis $90^{\circ}$ from horizontal. Left ધye, Spherical $-0.75 \mathrm{D}$, Cylindrical $-0.25 \mathrm{D}$, Axis $20^{\circ}$ from horizontal. The astigmatism in the left cye is negligible. So is that for 
times as great, when the vertical is the standard. The results of these subjects are given in Tables III and IV.

TABLE IV. Subject C. W. V.

Standard Horizontal, $60 \mathrm{~mm}$.

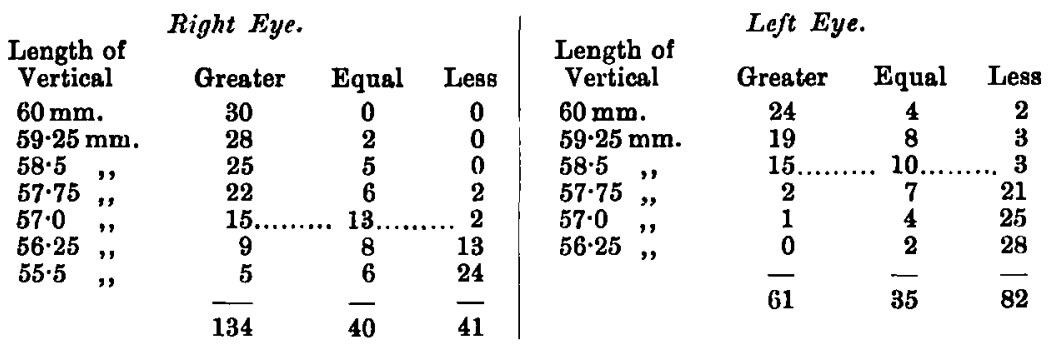

Standard Vertical, $60 \mathrm{~mm}$.

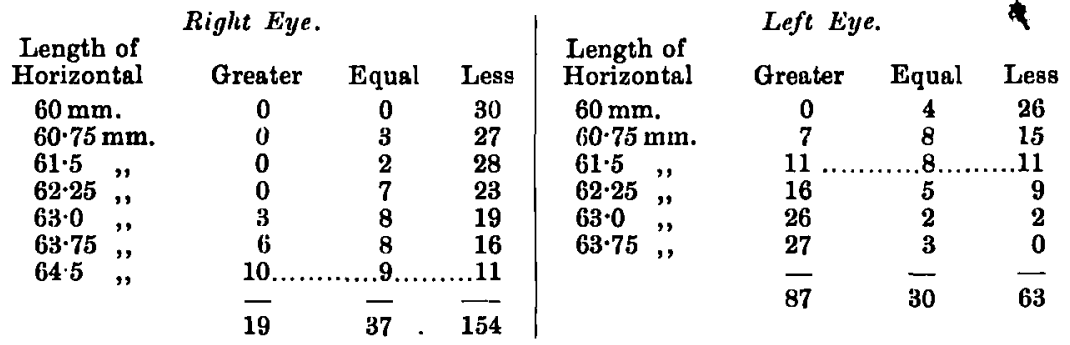

In Table $\mathrm{V}$ are given the results of subject $\mathrm{L}$. B., the only other subject who was declared quite free from astigmatism. The amount of illusion is practically the same for the two eyes when the horizontal is standard. With the vertical as standard a slight difference appears, which is made more obvious by the considerable difference between the totals.

In the case of subject C. W. V. extra variables had to be added for the right eye in the course of the experiments. These variables were a vertical line of $55.5 \mathrm{~mm}$. and a horizontal line of $64.5 \mathrm{~mm}$. These were added (without the knowledge of the subject) when it was remarked by the subject that he seemed to be giving far more judgments "vertical greater" than "horizontal greater" with the right eye. This subject was the writer and the apparatus was manipulated by his wife who understood the method thoroughly and had a free hand given her as

the right, judging from our previous tests. But if it did have any effect, it would be to blur the vertical and lengthen the horizontal, i.e. to decrease the illusion. And yet the illusiun is greater in the right eye than in the left. 
to what variables should be used. In spite of these added variables, the totals indicate an overwhelming majority of judgments "vertical greater" in the case of the right eye, while the opposite obtuined for the left eye.

TABLE V. Subject L. B.

Standard Horizontal, $60 \mathrm{~mm}$.

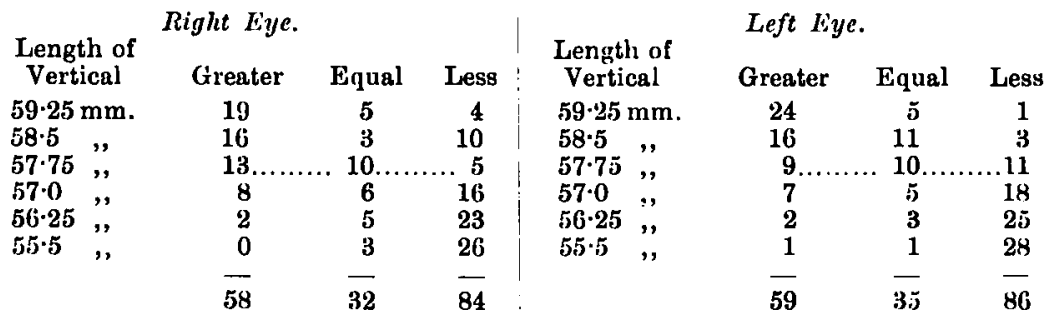

Standard Vertical, $60 \mathrm{~mm}$.

\begin{tabular}{|c|c|c|c|c|c|c|c|}
\hline & light liye & & & & Left $k$ & & \\
\hline $\begin{array}{l}\text { Length of } \\
\text { Horizontal }\end{array}$ & Greater & Equal & Less & $\begin{array}{l}\text { Luength of } \\
\text { Horizontal }\end{array}$ & Greater & Equal & Less \\
\hline $60.75 \mathrm{~mm}$ & 4 & 4 & 24 & $60.75 \mathrm{~mm}$ & 1 & 6 & 24 \\
\hline 61.5 & $\mathbf{3}$ & 7 & 20 & 61.5 & 3 & 7 & 20 \\
\hline $62-25$, & 2 & 8 & 21 & $62 \cdot 25$, & 9. & .7. & .14 \\
\hline ti3.0 ", & 9. & 8 & .13 & 63.0 & 18 & 7 & 5 \\
\hline $63 \cdot 75 "$ & 17 & 6 & 7 & $63.75 "$ & 22 & 4 & 3 \\
\hline 64.5, & 19 & 6 & 5 & 64.5, & 27 & 0 & 3 \\
\hline & 54 & 39 & $\overline{90}$ & & 80 & $\overline{31}$ & 69 \\
\hline
\end{tabular}

In view of the difference between the two eyes in the c:ises of E. R. V., A.E.T. and C. W. V., as shown by the method of right and wrong cases, and also of A.D. and A.S., as shown with three different standards by the method of mean error, it seems likely that the illusion is affected by some physiological factor. Exactly what this factor is we are unable to show upon the data before us. Possibly it is connected with some retinal quality, varying with the part of the retina stimulated. But whatever be its nature, this physiological factor may conceivably be the sole or main cause of the illusion. For, in the case of subjects A. E. T. and C. W. V., the difference between the two eyes is as great as the whole of the illusion for the left eye.

In the experiments described in this paper, the horizontal-vertical figure was fixated at the point of juncture of the two lines. Thus the vertical line would be in the upper peripheral field of vision. If the illusion is due to retinal conditions as suggested, it must be because the same line gives an impression of greater length if seen in the upper 
than if seen in the right periphery. Recent experiments by Dr H. C. Stevens ${ }^{1}$ support this view. He made subjects compare a disc seen by the fovea with similar discs seen in various positions in the peripheral field of vision, on the parallels of latitudes $10^{\circ}, 20^{\circ}$ and $25^{\circ}$ from the pole of the visual hemisphere. He found great variations according to the part of the periphery used, but there was a general tendency for a disc to appear larger in the periphery than a disc of the same size as seen by macular vision. What is of special interest for us is that in the case of the two subjects on whom exact quantitative experiments were performed "the enlargement is greatest in the vertical meridian." In the case of both observers the disc in the upper vertical field (on the circle $10^{\circ}$ from the line of direct vision) appeared greater than that in the corresponding position of the horizontal field. Stevens found similar variations even in the circle five degrees from the pole. The ends of the horizontal and vertical lines, as seen by my observers, would generally come within one or two degrees of the ten degree circle. The illusion would be explained if we suppose that the vertical, particularly. the part furthest in the periphery, will be subject to such magnification, more than the horizontal.

Further, there are interesting variations in the apparent size of Stevens's discs. Passing along, say, the vertical meridian, the disc may first appear to increase in size, then to decrease, and then to increase again. It may increase in the vertical and not in the horizontal meridian: or again it may increase in the upper vertical field, but not in the lower. Now if the horizontal-vertical illusion is connected with such retinal variations, we should be prepared to find considerable variations in the amount of the illusion according to the particular quadrant of the field of vision in which the lines of the figure appeared. And this was found to be the case ${ }^{2}$. Moreover, we should be prepared to find that sometimes, even when little or no difference is shown between the two eyes when we are using the horizontal standard and the smaller vertical variables (e.g. a horizontal of $60 \mathrm{~mm}$., and a vertical of $55-58 \mathrm{~mm}$.), a marked

1 Psychol. Rev. xv. 69. .

2 Cf. results of E. R. V. in my previous paper. Many such cases slso occurred in the series of experiments summarised in Tables XII and XIII in that paper; e.g. one subject showed an illusion of $5.1 \mathrm{~mm}$. in Fig. $B$ and a neyative illusion of $3 \cdot 1 \mathrm{~mm}$. in Fig. C (av. M.v. 1.99); another, illusion of $3.0 \mathrm{~mm}$. in Fig. C and negative illusion of $0.4 \mathrm{~mm}$. in Fig. B (av. M.v. 0.76). Further evidence of variation of this kind in the different parts of the retina to given in a research by Nicolai Poschoga, Psychol. Stud. vi. 384. He found that the threshold for discrimination of two points varied greatly with the part of the retina used. 
difference may nevertheless appear between the two eyes when we use a somewhat larger figure consisting of the standard vertical with the larger horizontal variables (e.g. a horizontal of $62-65 \mathrm{~mm}$., and a vertical of $60 \mathrm{~mm}$.). This again is what we have found in several cases. (See, for example, results of A. E. T., L. B. and C. W. V. in this paper.)

Of course one must not attach too much importance to the fact that in Stevens's experiments the discs were especially magnified in the vertical meridian, since the number of his subjects in the exact quantitative experiments was so small. But they were sufficiently numerous, with the support of quantitative experiments on other subjects, to show the great variability in size-perception in different parts of the retina.

It is not difficult to see that such peripheral variations may greatly influence the apparent length of the lines in the horizontal-vertical figure, so long as the eye fixates the point of juncture of the lines, the vertical line thus lying entirely in the upper periphery and the horizontal in the right periphery'. But what happens in the case of prolonged exposure, when the eye moves over the figure? Here, too, it may be urged $(a)$ that the eye tends generally to hover about the point of juncture, and then the lines are still within the upper vertical and right horizontal fields respectively; or $(b)$ that the eye moves to the end of one of the lines. Suppose the eye to hover about the end of the vertical line, then the vertical line will still remain in the vertical periphery though it is now in the lower half, while the horizontal is still in the right periphery though again it is in the lower half. Indeed, wherever the eye rests, a difference will be possible in the apparent size of vertical and horizontal lines due to retinal differences. But we shall expect this difference itself to vary as the eye moves. And hence (partly) may arise that uncertainty which characterizes the judgments with prolunged exposures. As Dawes Hicks and Rivers remark, "With the prolonged exposures...it was often extremely difficult to come to a decision," and oscillation of judgment sometimes occurred "even when the difference between the two lines was actually at the maximumi2."

Frequently my own subjects in trying to draw the one line equal to the other have given up the task in despair, saying that they felt their result was not right and yet did not know which way to alter it. Subject E. R. V., with whom prolonged exposures were used ${ }^{3}$, remarked

1 Speaking in terms of the field of vision; of course the upper vertical line will stimulate the lower periphery of the retins.

2 Op. cit. 255.

${ }^{3}$ Subject E. R. V., unlike the subjects of Dawes Hicks and Rivers (op. cit. 256) in prolonged exposures, seems to have got rid partially of this oscillation in the course of the 
that the lines "seemed to change in length" while she continued to look at them. All these observations are more comprehensible if we suppose that the lines vary in their apparent size, according to the part of the retina stimulated by them.

A further experimental confirmation of this theory seemed possible. Subject E. R. V. showed a much greater illusion for the figures $A L$ and $\mathrm{B}\lrcorner$ than she did for the figures $\mathrm{C} \neg$ and $\mathrm{D} \Gamma$. This would be explicable if a vertical line in the upper half of the field of vision appeared to her greater than one in the lower half.

Now this proved to be the case for E. R.V. in a marked degree. Using the same apparatus as before, I arranged that a vertical line should appear for a fraction of a second upon the glass screen seen by the subject E.R.V. Near the centre of the line a slight notch afforded a fixation point. The right eye ouly was used. The exposures were instantaneous, and the subject had to say whether the upper or the lower half of the line appeared the greater. By means of slides, these parts could be varied in length. Table VI shows the results. The lower half was first taken as standard and the upper half varied, and then vice versa.

TABLE VI. Subject E. R. V.

(a) Upper ' half' standard, $45 \mathrm{~mm}$.

(b) Lower 'half' standard, $55 \mathrm{~mm}$.

Length
lower ' ha
$50 \mathrm{~mm}$.
51, ,"
52 ",
53 ",
54 ",
55 ,"

$\begin{array}{ccc}\text { Greater } & \text { Equal } & \text { Less } \\ 4 & 1 & 16 \\ 5 & 2 & 14 \\ 8 \ldots \ldots \ldots \ldots . .4 \ldots \ldots \ldots . . & 9 \\ 11 & 3 & 7 \\ 16 & 3 & 2 \\ 17 & 4 & 0 \\ \frac{61}{61} & -17 & -48\end{array}$

Length of upper'half' Greater Equal Less

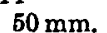

49 ",

48 ",

47 ,

$46 "$

45,

$\begin{array}{ccc}\text { Greater } & \text { Equal } & \text { Less } \\ 19 & 1 & 1 \\ 15 & 3 & 3 \\ 15 \ldots \ldots \ldots \ldots .4 \ldots \ldots & 2 \\ 7 & 3 & 11 \\ 5 & 6 & 10 \\ 0 & 1 & 20 \\ \overline{61} & \overline{18} & -47\end{array}$

It will be seen that, on the average, an upper 'half' of $45 \mathrm{~mm}$. is judged equal to a lower 'half' of $52 \mathrm{~mm}$., a difference of $7 \mathrm{~mm}$. This experiments, as she gave no "equal" judgments in the last section (one-third) of the experiments; but she had an exceptional amount of practice, her judgments numbering nearly four thousand tive hundred.

1 When the writer fixates the juncture of the lines with one eye and then slowly moves the eye upwards along the vertical, the upper end of the vertical appears first to appruach the point of juncture and then (when the eye has travelled about half-way up) to recede again. The same happens with the horizontal though not to the same extent. The lines should be at lesst two inches in length and it is well to mark the end with a cross. But this may be an illusion of movenent, and not due to the passing of the line image over different parts of the retina. It does not, however, seem to occur to the same extent with the left eye as with the right. 
is more than ample to account for the difference between the amount of illusion for the figure of the upper 'quadrants' and that fur the lower 'quadrants' in the case of E. R.V.

Summing up, we may say that lines of evidence from various points lead to the theory that the illusion is caused by variations in the apparent size of a line according to the part of the retina stimulated.

\section{Effect of practice.}

The effect of practice in this illusion proves to be highly interesting, but somewhat difficult to explain. One fact is clear-the illusion may actually increase with practice, not only with momentary but also with prolonged exposures. No such observation has been made, I believe, in the case of any other illusion ${ }^{1 .}$

Unfortunately it is impossible to give the practice effects in the case of all subjects, for two reasons. First, it was often impossible to obtain regular sittings, an interval of four days or even a week sometimes intervening between two sittings, so that practice effects were lost. Secondly, it was necessary in several cases in the course of the experiments to add an extra-long horizontal variable (or an extra-short vertical), and to abandon the use of the shortest horizontal (or longest vertical). This had to be done because the illusion proved to be greater, at least after a little practice, than the preliminary tests had indicated, and the excess of judgments "vertical greater" proved harassing to some subjects. This necessary alteration of the lines, though itself possibly an indication of an increase of the illusion with practice, renders impossible a strict comparison of the first set of judgments with the last.

The subject whose sittings were most regular and who had most practice was E. R. V. with whom prolonged exposures were used. With very few exceptions she had two or even three sittings each day. The results are given in Table VII and indicate a marked increase of the illusion with practice, more especially with the right eye. The first set of ten judgments with each variable is taken, and the proportion of "vertical greater" to "horizontal greater" judgments is shown by the figures given.

In Tables VIII and IX I also give the results in the case of subjects W. A. and C. W. V. who also show an increase with practice.

1 E. O. Lewis found a slight increase in the Müller-Lyer illusion in two subjects, but only for momentary exposures and during a short series of experiments. See this Journal, II. 298. 


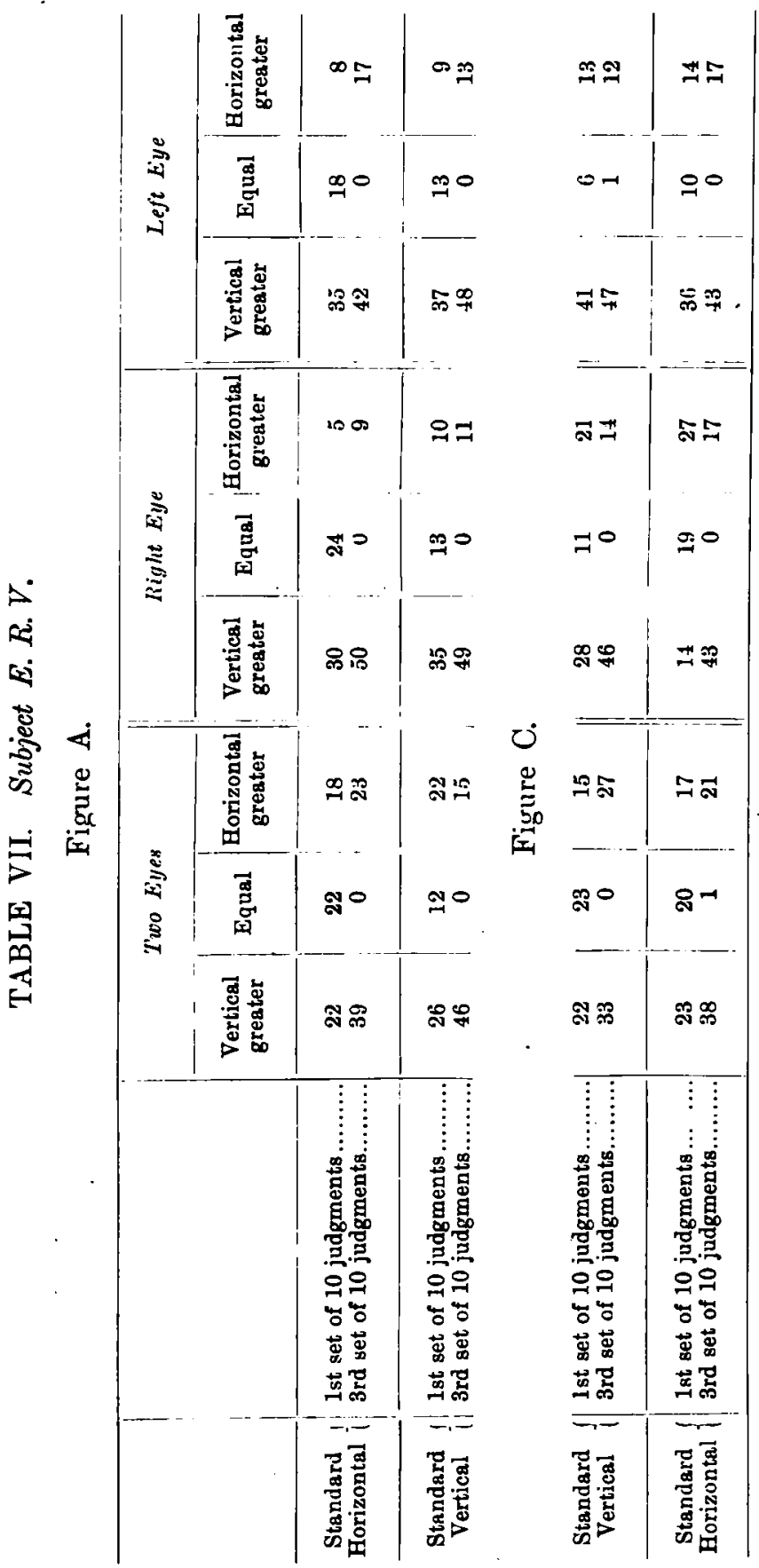


In comparing the figures notice should be taken, not only of the increase of the number of judgments "vertical greater," but also of the decrease in the number of judgments "horizontal greater." In the case of the left eye of subject E. R.V. the number of judgments " horizontal greater" generally increase, thus balancing to a considerable extent the increased number of "vertical greater" judgments.

TABLE VIII. Subject W. $A$.

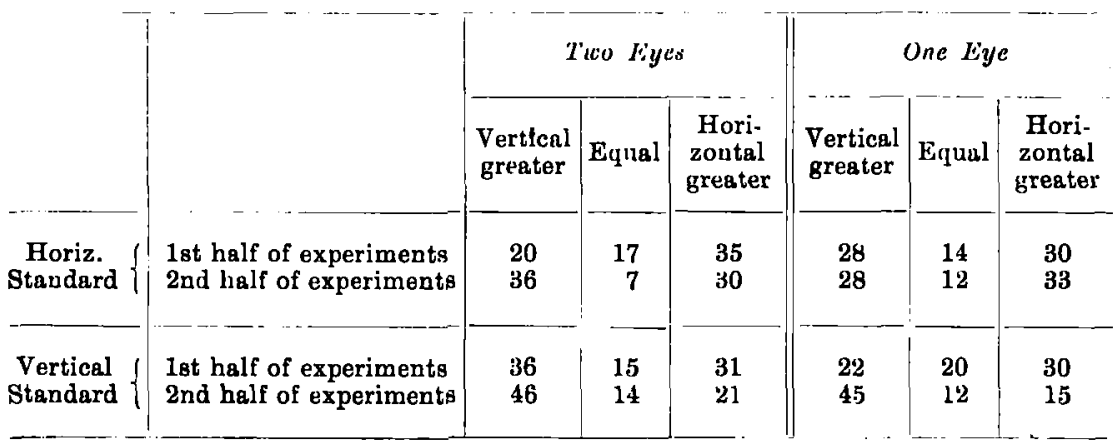

TABLE IX. Subject C. W. V.

\begin{tabular}{|c|c|c|c|c|c|c|c|}
\hline & & \multicolumn{3}{|c|}{ Right Eyc } & \multicolumn{3}{|c|}{ Left Eye } \\
\hline & & $\begin{array}{l}\text { Vertical } \\
\text { greater }\end{array}$ & Equal & $\begin{array}{c}\text { Hori- } \\
\text { zontal } \\
\text { greater }\end{array}$ & $\begin{array}{l}\text { Vertical } \\
\text { greater }\end{array}$ & Equal & $\begin{array}{l}\text { Hori- } \\
\text { zontal } \\
\text { greater }\end{array}$ \\
\hline $\begin{array}{l}\text { Horiz. } \\
\text { Standard }\end{array}$ & $\begin{array}{l}\text { 1st set of judgments" } \\
\text { Last set of judgments }\end{array}$ & $\begin{array}{l}39 \\
56\end{array}$ & $\begin{array}{r}18 \\
4\end{array}$ & $\begin{array}{l}15 \\
10\end{array}$ & $\begin{array}{l}17 \\
26\end{array}$ & $\begin{array}{r}15 \\
5\end{array}$ & $\begin{array}{l}27 \\
30\end{array}$ \\
\hline $\begin{array}{l}\text { Vertical } \\
\text { Standard }\end{array}$ & $\begin{array}{l}\text { 1st set of judgments* } \\
\text { Last set of judgments }\end{array}$ & $\begin{array}{l}45 \\
64\end{array}$ & $\begin{array}{r}12 \\
3\end{array}$ & $\begin{array}{l}8 \\
4\end{array}$ & $\begin{array}{l}19 \\
27\end{array}$ & $\begin{array}{r}11 \\
7\end{array}$ & $\begin{array}{l}30 \\
\mathbf{2 4}\end{array}$ \\
\hline
\end{tabular}

- With this subject I have taken the first two-thirds of the judgments, and halved the numbers in order to compare them with the numbers of the last third of the judgments. This was unfortunstely necessitated by lack of clear distinction between records of the first and second sets of judgments.

With C. W. V. the totals are greater for the right eye, because more variables were used for this eye than for the left.

It will be seen that E. R. V. in the case of Fig. A shows an increase in the illusion for two eyes and the right eye (when vertical is standard), 
but the illusion for the left eye remains practically the same ${ }^{2}$. It is remarkable that in all cases the "equal" judgments entirely disappear in the last set of judgments. The increase of the illusion in the case of the right eye and two eyes is cansed largely by these equal judgments being transferred to the column of "vertical greater" judgments. This disappearance (or decrease) of the number of equal judgments seems to indicate a more definite and decided attitude of judgment in the later sittings ${ }^{2}$. This more decided attitude is shown by all subjects who show an increase in the illusion with practice (E. R. V., W.A., and C. W. V.), and it is remarkable that the opposite effect (i.e. an increase in the number of "equal" judgments) is shown by the only subject (A. K.) who shows a slight decrease, in the illusion with practices.

In the case of subject C. $O$. K. the amount of the illusion remained practically the same throughout, and in her case it is notable that from the first her answers were prompt and definite. Throughout a long set of experiments (she had two sets, with and without glasses) she never, even at the start, gave a single "equal" judgment, nor even ove in the form "vertical greater or equal" or " horizontal greater or equal."

L. B. also showed no change of the illusion with practice, and no decrease in the number of "equal" and indefinite judgments. But unlike C.O.K., who was prompt and confident from the beginning, L. B. was the most hesitant of all my subjects, and this hesitancy did not decrease with practice in his case. To the end he interjected remarks that it seemed to him that his results could be of little value as it was so hard to form judgments and that these were probably very inconsistent, though as a matter of fact he was as consistent as the average subject. It should be noted that the sittings in the case of L. B. were generally separated by about a week.

1 The results are broadly the same for Fig. $C$, in which again very little increase in illusion was shown by the left eye. Practice effects could not be calculated for Figs. B and $D$ owing to the second reason mentioned above.

2 This subject explained that by "equal" she meant "I cannot tell the difference." This was the genersl interpretation, though two subjects asserted that sometimes the equal judgments were decided judgments of positive equality, and these two, A. E. T. and C. W. V. were those who had had most experience in introspeetive work.

${ }^{3}$ This only refers to the right eye. In the first set of judgments with the right eye A. K. gave 9 "equal" judgments, in the last set 20 . I should state that this subject's sittings were by no means regular. He did not acquire any information as to the nature of the illusion during the course of the experiments. But it is possible that he began to suspect the presence of some illusion; for example, he volunteered the remark that he seemed to give the judgments "vertical greater" more readily than the judgments "horizontal greater." 


\section{Interpretation of the effects of practice.}

If the illusion be due to physiological causes it seems possible that these various practice effects may be explained as follows. At first the immediate sensory impressions are complicated with and interpreted by experience of the comparative lengths of lines gained in drawing or in seeing objects known to be square, and so forth. Professor Dawes Hicks and Dr Rivers attribute the indefiniteness of long exposure judgments to a similar source ${ }^{1}$. Now it seems possible that with practice the subjects may yield themselves and their judgments more and more to the immediate sensory impressions made by the lines, thus throwing off the correcting influences of experience. Hence only after practice would the physiological conditions have their full original effect. Professor Stout suggests to me, as an interesting case analogous to this, the regaining on the part of the artist of what Ruskin calls the "innocence of the eye," when he learns to see things "as they really are."

No doubt it is conceivable that a psychological cause might also be more effective after similar practice. But it seems more likely that psychological complications should lose rather than gain influence as judgments become more mechanical. This is true of mental processes in general, and it has been found that in the case of several psychological illusions practice causes the illusion to decrease markedly or even to disappear entirely. At least it seems clear from the above results that those psychological factors which lead to hesitancy and uncertainty tend to disappear with practice?

It will be noticed (Table VII) that practice had a much less pronounced effect on the left eye of E.R.V. than on the right eye. Now this left eye is slightly the more astigmatic, and E.R.V. remarked that it was harder to judge with it and that she became more easily fatigued with its use than with the right eye. Possibly then the 'mechanical' attitude was not so easily acquired, though the final

1 op. cit. 257.

2 It is interesting to note that the right eye of E. R. V. also showed a steady increase with practice of the illusion of the over-estimation of the upper half of a verticnl line compared with the lower half. Adding results of both standards we get the foilowing:

\begin{tabular}{|c|c|c|c|c|}
\hline \multirow{2}{*}{\multicolumn{2}{|c|}{ of 7 judgments }} & \multicolumn{2}{|r|}{$\begin{array}{l}\text { Number of times } \\
\text { Upper half judged greater }\end{array}$} & \multirow{2}{*}{$\begin{array}{c}\text { Number of times } \\
\text { Lower half judged greater } \\
\qquad 11\end{array}$} \\
\hline & & $\ldots$ & 30 & \\
\hline 2nd & , & $\ldots$ & 38 & 36 \\
\hline 3rd & ," & $\ldots$ & 41 & 31 \\
\hline
\end{tabular}


disappearance of the " equal " judgments suggests that it was acquired eventually.

One further speculation I suggest in the most tentative manner. It is remarkable that, both with E.R. V. and C. W. V. it is the more efficient eye which shows the greater increase of the illusion with practice. Is it possible that in ordinary estimations of shape and size we rely mainly upon the impressions received through the better eye, when one is superior to the other? The writer is only slightly more myopic in the left eye than in the right, but he has found a constant tendency to close the left eye (when without glasses), and to rely upon the right only. In such subjects, when the differences are not compensated by glasses, is it not possible that through one eye: being habitually more used, that eye alone becomes fully "trained" ? Thus the primary physiological illusion might be (partially) corrected by experience only or mainly in one eye, viz. the inore efficient one. If this were so the less efficient eye, in such experiments as these, might show its full original degree of illusion at the start. It would have little or nothing to "unlearn." Hence there would only be an increase of the illusion with practice, in the case of the more efficient "trained" eye (as we find is the case with E. R.V. and C. W. V.), an increase which would occur in so far as these effects of training and experience were lost in the more mechanical attitude of the subject. If this could be established it would throw an interesting light on the relationship of the respective (or combined) contributions of the two eyes to the processes of association, perception and interpretation.

In view of the effect of practice on the amount of the illusion the following question arises. If the increase of the illusion with practice is associated with increased decisiveness of judgment, is it possible that the differences between the two eyes are similarly causally related to the latter and are not due to physiological conditions? It seems to me that the facts are against this.

For there is no regularity of connexion between (1) size of illusion in respective eyes and (2) efficiency of the respective eyes, or (3) decisiveness of judgment with respective eyes.

Thus in the case of subject A. E. T., (1) the illusion is much greater, seen with the right eye; but (2) the left eye is slightly the more

1 It is of course known that when one eye is markedly defective the visual impression received by means of it may be ignored entirely and so squint encouraged. See C. S. Myers, Text Book of Experimental Psychology, 1911, 1. 266. Cf. also A. A. Bradburne, Ophthal. mology, July, 1909. 
efficient, from which one would expect that certainty should be greater; while (3) the number of indefinite judgments is practically equal for the two eyes.

On the other hand, in the case of C. W. V., (1) the illusion is much greater when seen with the right eye; (2) the efficiency of the two eyes was presumably the same, as glasses were worn during experiments ; and (3) the number of indefinite judgments was practically the same (proportionately) for each eye.

Or to put it briefly, with these two subjects the illusion is twice or three times as great with the right eye as with the left, and yet the number of indefinite judgments is the same for both eyes.

Lastly, in subject E. R. V., (1) the illusion is considerably greater in the left eye; (2) the right eye has slight superior efficiency; but (3) the number of equal (indefinite) judgments is almost the same (left eye 129 , right eye 140).

These facts, however, do not constitute a difficulty for a physiological theory, since the illusion may be much greater to start with in one eye than in the other. Changes due to practice (viz. increase of illusion with greater definiteness of judgment) may affect the right eye more than the left, and yet the left may show a greater illusion; or practice may affect the left more, and the left eye may show a greater illusion; or practice may affect the right eye more and the right eye may show a greater illusion and so on, and these are just the various combinations of results which we do obtain.

\section{The physiological factor involved in the illusion.}

The exact nature of the physiological factor involved in the horizontal-vertical illusion is not primarily a question for the psychologist. We may be content with the supposition that those conditions, whatever they may be, which give rise to variations in the apparent size of objects as seen by different parts of the periphery of the retina, differ from the conditions at the centre more in the vertical direction than they do in the horizontal direction. Poschoga found that the threshold of discrimination of two points is much higher in the periphery than near the fovea, and that the difference increases as we get further from the fovea. This might seem to be readily explained by the fact that the retinal elements are wider apart at the periphery than near the centre. But we have to correlate these facts with the fact that objects look larger in peripheral than in macular vision. Now 
this is quite the opposite to what we find as regards the sense of touch. In the case of touch an object or a line appears largest when in contact with that region of the skin where the threshold of discrimination is lowest. There is, however, no direct proportion between the threshold of discrimination and impressions of size. And for various reasons it would seem that the threshold of discrimination is not to be taken as the unit of measurement of distance either in sight or touch ${ }^{1}$.

Certainly as regards vision we may conclude that the unit of size cannot be given merely by the stimulation of one retinal element, at least that this is not a constant unit for all parts of the retina. But the distance between the sensitive elements in the periphery may in some way give rise to an impression of greater size more than sufficient to compensate for the fact that fewer elements are stimulated by any given object at the periphery than near the centre.

Or again, we know that we may get "a difference of perceived extent by the stimulation at various intensities, of a single pressure spot, and of a single retinal cone ${ }^{2}$." If some cones are more sensitive than others, is it not possible that some of their superior activity is translated into an experience of increased extensity beyond that of others? It has been suggested that, as most of our sensations important for life and well-being come from stimuli below the horizontal plane of vision, we may expect the upper half of the retina to be more sensitive (or our preceptiou by means of it more accurate) than the lower. But greater accuracy does not necessarily imply greater size: and further, this theory would not explain the illusion in the figures $\downarrow$ and $L$ when the point of junction is fixated; for the vertical would in this case stimulate the lower part of the retinal field.

Of course it still remains possible that the same unit of size has come to mean more, and appear more, in the vertical than in the horizontal meridian. Some obscure psychological factor may be at work here. For example, it is possibly harder to attend to objects in the vertical than in the horizontal periphery, owing to our greater practice with the widely extended horizontal field. And it is conceivable that greater difficulty of attention should be translated into greater apparent size, though one would think that the opposite would be more likely. But we must recall the facts that the illusion may be very different in amount for the two eyes respectively, and that this difference may be

1 See Poschoga, op. cit. 427. Also Titchener, Textbook of Psychology, II, 322 and 327,

2 Titohener, Textbook of Psychology, Ir. 327. 
as great as or even greater than the whole amount of illusion for one of the eyes. Such facts must surely be explained by a purely physiological factor. They cannot be explained merely by supposing that the more efficient eye has had better training in drawing, observation of square objects, etc., and so gives a smaller illusion. For in some cases it is the better eye which gives the greater amount of illusion, markedly so in the writer's own case. On the whole then the simplest explanation seems to be that there are original quantitative differences in the sensations mediated by different meridians of the retina, a relative magnification generally taking place in the vertical periphery. This view we find confirmed by the changes in the relative apparent sizes of a disc or line seen in different portions of the peripheral field of vision, and by the fact that the horizontal-vertical illusion may be present in different degrees in different quadrants of the visual field, even for the same eye.

\section{Summary of results and conclusions.}

(1) It appears that the horizontal-vertical illusion is unaffected by astigmatism not exceeding $\pm 1.5 \mathrm{D}$, unless other optical defects also cause a blurring of the figure.

(2) But astigmatism of $\pm 2 \mathrm{D}$, in some subjects at least, is enough to alter the apparent relative lengths of the lines in the horizontalvertical figure.

(3) Subjects entirely free from astigmatism, or whose astigmatism is so slight as to be negligible, still show a marked difference between the amount of the illusion for the right eye and that for the left eye. This must apparently be ascribed to some physiological cause.

(4) As this difference between the two eyes is sometimes greater than the whole amount of illusion for one of the eyes, it seems possible that this physiological factor may be the sole or at least the main cause of the illusion.

(5) Some clue as to the locus of this physiological factor may be afforded by the fact that an object appears of different sizes according to the part of the peripheral field of the retina on which its image falls.

(6) The physiological theory here suggested accounts for the apparent variation of the comparative lengths of the lines as one fixates different points of the figure.

(7) Apparently the usual effect of practice is to increase the illusion. The increase may be much greater in the case of one eye 22-2 
than the other. It is generally accompanied by a great decrease in the number of judgments that the horizontal and vertical lines are of equal lengtb. In the two cases in which the practice effect was greater with one eye than the other, it was the more efficient eye that showed the greater increase of the illusion with practice.

(8) This increase of the illusion with practice seems to be due to the adoption of a more 'mechanical' attitude on the part of the subject, in which he yields himself more completely to the immediate sensory impressions.

I wish to tender my thanks to Dr Rivers for his continued interest in this research, and to the subjects who so kindly submitted to the numerous tests, viz. Professor A. E. Taylor, Dr J. Scott, Professor L. Brehaut and my wife. These, together with the subjects of the previous series of experiments, contribited in all over fifteen thousand judgments.

(Manuscript received 28 February, 1912.) 